\title{
1 Quantifying plasticity in vessel grouping - added 2 value from the image analysis tool ROXAS
}

3

4

5

6

Georg von Arx ${ }^{1,3}$, Christoph Kueffer ${ }^{2}$, Patrick Fonti ${ }^{1}$

${ }^{1}$ Swiss Federal Institute for Forest, Snow and Landscape Research WSL, Birmensdorf, Switzerland

${ }^{2}$ Swiss Federal Institute of Technology ETH, Zurich, Switzerland

${ }^{3}$ (Corresponding author) e-mail: georg.vonarx@wsl.ch; phone: +41-44-7392 316, fax: +4144-7392 215

Article Type: Technical Note

Running headline: Quantifying plasticity in vessel grouping

\section{Counts:}

\section{Abstract:}

Main body:

Introduction:

Materials and Methods:

Results and Discussion:

Acknowledgements:

Number of Tables:

Number of Figures:
211

3039

743

1002

1240

54

2

This document is the accepted manuscript version of the following article: 


\section{Abstract}

The functional role of the connectivity of the xylem network, especially the arrangement of solitary and grouped vessels in a cross-section, has already been discussed in the literature. Vessel grouping may improve hydraulic integration and increase resilience to cavitation through redundancy of hydraulic pathways. Alternatively, a high degree of hydraulic integration may facilitate the spread of cavitations among neighboring vessels. Here we show how automated image analysis tools such as ROXAS (see www.wsl.ch/roxas) may greatly enhance the capacity for studying vessel grouping while avoiding some methodological limitations of previous approaches. We tested the new analysis techniques by comparing the xylem network of two populations of the herbaceous species Verbascum thapsus collected at a dry and moist site on Big Island (Hawaii, USA). ROXAS accurately, objectively and reproducibly detected grouped and solitary vessels in high-resolution images of entire root cross-sections, and calculated different and partly novel vessel grouping parameters, e.g. the percentage of grouped (vs. solitary) vessels among different vessel size classes. Individuals at the dry site showed a higher degree of vessel grouping, less solitary vessels, greater maximum vessel sizes and an increase of the percentage of grouped vessels with increasing vessel size. The potential, but also some limitations of automated image analysis and the proposed novel parameters are discussed.

\section{Keywords}

alternative hydraulic pathways, automated image analysis, grouped vessels, hydraulic integration, solitary vessels, spreading of embolism, spatial vessel arrangement, vessel grouping index 


\section{Introduction}

The connectivity among vessels, also referred to as vessel grouping in a cross-sectional view (Carlquist 1984; Loepfe et al. 2007; Carlquist 2009), is increasingly attracting research interest as a potentially important hydraulic trait in angiosperms, particularly in a context of changing climate. This is because of the outstanding importance of vessels for watertransport. It is widely known, for example, that efficiency potentially increases with the fourth power of vessel radius according to the Hagen-Poiseuille law (Tyree \& Ewers 1991), but also that wider vessels are arguably more susceptible to hydraulic failure by drought-induced cavitation, i.e. the rapid phase change of liquid water to vapor ("safety vs. efficiency tradeoff”; e.g. Hacke \& Sperry 2001; Hacke et al. 2009; Cai \& Tyree 2010). The importance of the topology of vessel networks for plant water transport and plant-water relationships in general lies in the water-permeable pit pores formed in the cell walls between neighboring vessels. Previous studies observed an evolutionary trend towards an increase of vessel grouping with increasing water limitation (Carlquist 1966; Lopez et al. 2005; Lens et al. 2011; Carlquist 2012), although some studies also found inconsistent patterns or no relationship (Baas \& Carlquist 1985; Baas \& Schweingruber 1987). Similarly, a consistent increase of vessel grouping in response to water limitation and wounding was observed within species (Robert et al. 2009) and individuals (Arbellay et al. 2012), respectively.

However, the functional role of vessel grouping remains controversial. Several scientists suggested that a high degree of vessel grouping may provide alternative pathways when water transport through a vessel is blocked by drought-induced embolism but bypassed through one or more still functional vessels from the same vessel group. (Baas et al. 1983; Zimmermann 1983; Carlquist 1984; Tyree et al. 1994). In this case vessel grouping improves the hydraulic redundancy and reduces the potential loss of water transport capacity associated with cavitation. Another benefit of vessel grouping is related to the observed increasing permeability of intervessel pit membranes upon changes in the ionic concentration of the xylem sap which can occur during water limitation ("ionic effect", Jansen et al. 2011; Nardini et al. 2012). Finally, cavitations may be more easily removed in clustered than solitary vessels, although this has so far only been postulated theoretically (Holtta et al. 2006). In contrast, an increase of vessel grouping can also bring disadvantages. For example, vessels in a dense network have more contact surface, which enhance the risk of cavitation spreading from one vessel to the next by the aspiration of air through the pit pores (Sperry \& Tyree 1988; Brodersen et al. 2013) known as air-seeding hypothesis (Alder et al. 1997; Wheeler et al. 2005; Loepfe et al. 2007). Furthermore, vasicentric tracheids, where present, potentially offer a subsidiary conductive tissue that would lower the value of hydraulic integration by vessel grouping (Carlquist 1984; Carlquist 2001), but likely not invalidate it (Sano et al. 2011). The empirical evidence from the relatively few quantitative studies about the functional role of vessel grouping is insufficient to clarify the controversy about the functional role of vessel grouping under water limitation.

Vessel grouping has been often quantified visually from the xylem cross-section (but see Mencuccini et al. 2010; Martínez-Vilalta et al. 2012). However, this approach bears several potential limitations. First and most importantly, the coverage is usually restricted to a rather small sub-area of the entire sample and thus is not representative to describe the whole variability (but see Arbellay et al. 2012). Secondly, the results are hardly reproducible because there is usually some interpretation involved as to whether two vessels are truly connected through pit pores or not. Thirdly, the possibilities to quantify different aspects of the connectivity of the xylem network beyond grouped vs. solitary vessels and group size are limited. These methodological shortcomings can be significantly reduced through the use of 
image analysis tools for automatic detection and quantification of conduits. Advancements in digital imaging and improved computer performance allow nowadays to perform analysis of large samples while using objective criteria for the definition of vessels grouping. In this article, we present a new approach for quantifying several and partly novel parameters of vessel grouping in entire cross-sections and tree cores using the image analysis tool ROXAS grouping analysis with data of the forb Verbascum thapsus collected at two sites with contrasting climate, and suggest some directions for future studies into vessel grouping.

\section{Materials and Methods}

\section{Test dataset}

To test the potential of whole-sample grouping analysis, and to investigate the plasticity of several aspects of vessel grouping within a species, we collected roots of 14 individuals of Verbascum thapsus L. (Scrophulariaceae) at two contrasting sites on Big Island, Hawaii, USA between March $28^{\text {th }}$ and April $24^{\text {th }} 2008$. The two sites represent the dry and wet margin of the distribution of $V$. thapsus in the selected study area (C. Kueffer, unpublished data). The first site ('dry' site), was at $600 \mathrm{~m}$ asl on a northwesterly, leeward slope (mean annual temperature: $20.5^{\circ} \mathrm{C}$, total annual precipitation: $790 \mathrm{~mm}, \mathrm{n}=6$ ). The second site ('moist' site) was at $1700 \mathrm{~m}$ asl on an easterly, windward slope $\left(14.5^{\circ} \mathrm{C}, 2380 \mathrm{~mm}, \mathrm{n}=8\right)$. Plants at both sites grew on lava gravel characterized by poorly developed soil and sparse vegetation cover. The two sites were $60 \mathrm{~km}$ apart. The study species $V$. thapsus is a stout, erect herbaceous species that generally produces a rosette in the first and a flowering stalk in the second growing season, after which it dies. $V$. thapsus is considered a problematic invasive species (Kueffer et al. 2010), and it is known to show very high plasticity in aboveground growth patterns in response to environmental variability (Parker et al. 2003; Seipel et al. 2013). All selected individuals were flowering when roots were collected. Plants from the dry site were $1.30 \pm 0.15 \mathrm{~m}$ tall and plants from moist site $0.64 \pm 0.08 \mathrm{~m}$.

After collection, the proximal part of the main root of each individual was conserved in a 50\% ethanol solution. Complete $30-50 \mu \mathrm{m}$ thick cross-sections near the proximal end (root collar) were produced using a sledge microtome and stained with phloroglucinol / $\mathrm{HCl}$ causing reddish coloration of lignified structures (here the cell walls of secondary xylem vessels and lignified parenchyma cells). Stained cross-sections were then photographed through the oculars of a transmitting microscope (Olympus BX51, 20x magnification) using a standard digital camera (Nikon Coolpix 990). Multiple overlapping images were taken from each sample and stitched together using PTGui (New House Internet Services B.V., Rotterdam, $\mathrm{NL})$ to obtain high-resolution images $(0.477$ pixels $/ \mu \mathrm{m})$ of the entire cross-sections (Fig. 1a,b; (von Arx et al. 2012)). Digital images of cross-sections were then analyzed using ROXAS, and automatic grouping results were compared to manual inspection of the digital images in three randomly chosen individuals. Manual inspection was performed by systematically counting the vessel groups of different sizes in the digital images. Only vessels from the root sections representing the flowering year in 2008 according to herb-chronological analysis were considered for analysis (von Arx \& Dietz 2006), and from these only vessels having a cross-sectional lumen area ('vessel size') $\geq 250 \mu \mathrm{m}^{2}$, because below this size vessels could not be unambiguously distinguished from parenchyma cells. 
From a functional perspective, there is no unique best parameter to quantify vessel grouping, because several properties become relevant depending on the ecophysiological processes considered. We therefore considered five different parameters to quantify vessel grouping (Table 1). The first parameter was the vessel grouping index $V_{G}$ proposed by Carlquist (2001), i.e. the mean number of vessels per vessel group (counting a solitary vessel as 1, a pair of vessels in contact as 2 , etc.), which also corresponds to the most commonly used parameter in the literature. While $V_{G}$ provides a good general estimate of vessel grouping, it misses information about variation. Three other parameters were thus defined: the fraction of solitary vessels $\left(V_{S}\right)$, the mean group size of non-solitary vessels $\left(V_{M}\right)$, and the relative frequency distribution of vessel groups $\left(F D_{G}\right)$. The rationale behind using $V_{G}, V_{S}$, and $V_{M}$ is that two individuals may have the same value of $V_{G}$, but one of them may have smaller vessel groups $\left(V_{M}\right)$ and thus fewer solitary vessels $\left(V_{S}\right)$, than the other (Fig. 2). Compared to $V_{G}$ and $V_{M}$, $F D_{G}$ better represents the range of vessel grouping and the relative importance of different group sizes for overall connectivity. Finally, the functional meaning of vessel grouping may not be the same for wide vessels (expected to cavitate first) as for narrow vessels (expected to provide an hydraulic safety net). We therefore calculated the percentage of grouped (nonsolitary) vessels for different vessel size classes $\left(R G_{V A}\right)$ as a fifth parameter.

\section{Image analysis tool ROXAS}

ROXAS is an image analysis tool for quantifying the xylem anatomy in cross-sectional samples of trees (angiosperms and conifers), shrubs and herbaceous plants. It is based on the image manipulation and registration capabilities of Image Pro Plus $\geq$ v6.1 (Media Cybernetics, Silver Spring, Maryland, USA), and adds own code and algorithms to automatically detect conduits and, with some limitations, tree-ring boundaries (von Arx \& Dietz 2005; Fonti et al. 2009). The user can manually edit the automatically-generated results, and obtains a large set of output parameters for the entire sample including ring width, conduit lumen area, and vessel grouping parameters. ROXAS is, under certain conditions, free of charge for the research community (see www.wsl.ch/roxas for more details and a download link).

The identification of grouped vs. solitary vessels in the considered plane of the xylem crosssection is based on distance criteria: to decide whether two neighboring vessels are touching each other, ROXAS first calculates the Euclidean distance $d$ between their centroids and then subtracts the radius of each vessels to obtain the distance $d$ ' between the outlines of the vessel lumina (Fig. 3). The radius of the vessels is thereby adjusted for elliptical vessel shape. If $d^{\prime}$ is equal or smaller than the empirically determined threshold $d_{t h r}$ that approximately corresponds to the double-cell-wall thickness of the two neighboring vessels, they are considered as touching and hydraulically connected through pits. This approach does not discriminate different intervessel contact length, i.e. the length of vessel wall in contact with a touching vessels as seen in the cross-section (Jansen et al. 2011; Scholz et al. 2013); however, a longer contact length will indicate more intervessel pits and therefore potentially better hydraulic integration of the touching vessels. 


\section{Results and Discussion}

\section{Plasticity of vessel grouping within species}

Overall, 32,000 vessels were measured in the roots of the 14 individuals (mean number per individual: dry site $-3,800$, moist site $-1,150)$. The individuals from the two sites differed significantly in the vessel grouping index $\left(V_{G}\right)$, vessel solitary index $\left(V_{S}\right)$, and the mean size of grouped vessels ( $V_{M}$; Fig. 4). Individuals growing at the dry site had more grouped and fewer solitary vessels, and mean group size was also larger than in plants at the moist site. Similarly, the relative frequency of different group sizes $\left(F D_{G}\right)$ also differed substantially, with plants growing at the dry site having larger maximum group sizes and a higher representation in all group sizes except the solitary ones (Fig. 5). Wider vessels were more often grouped than narrower vessels in the individuals at the dry site, while at the moist site, vessel grouping was independent from vessel size (Fig. 6). An example of how ROXAS detected vessel groups is shown in Fig. 1c,d.

These results are consistent with other studies finding a positive relationship between vessel grouping and habitat dryness (Carlquist 1966; Robert et al. 2009; Lens et al. 2011; Carlquist 2012). Our results are also in accordance with a previous study by Robert et al. (2009) where considerable plasticity in vessel grouping patterns was found within species. Our findings suggest that a higher degree of grouping is both attained by fewer solitary vessels and larger groups of vessel multiples, which must not inevitably be linked (cf. Fig. 2). The dependence of vessel grouping on vessel size is an intriguing result: based on our limited data set, the increased hydraulic integration of the widest vessels in dry-site plants could enhance pathway redundancy, if some of these vessels cavitate while other (smaller) vessels of the same vessel group remain functional.

\section{Accuracy of automatic detection of vessel grouping}

The automatic results for $V_{G}, V_{S}$, and $V_{M}$ differed from those obtained by manual inspection by $4 \%$ and less. (Table 2). The differences in the frequency distribution of different group sizes $\left(F D_{G}\right)$ were, with a few exceptions, very small as well. The accuracy of the percentage of grouped vessels per vessel size class $\left(R G_{V A}\right)$ could not be checked by manual inspection, but should behave similarly, as it is also based on detected vessel groups. This demonstrates that differences of the ROXAS from the manual inspection approach are negligible. This accordance depends on correct vessel detection and recognition of vessel outlines (avoiding under- and overestimation of vessel lumen area) and a sensible distance threshold $d$ ' for the distinction of touching vs. non-touching vessels (cf. Materials and Methods). In addition, it was sometimes ambiguous by manual inspection, whether two closely positioned vessels were touching or not, which likely explains the few discrepancies to automatic results for $F D_{G}$.

\section{Limitations of (automatic) vessel grouping analysis in cross-sections}

Two limitations require consideration when investigating vessel grouping in cross-sections. First, when performing image analysis automatically or manually, a minimum cut-off vessel size has usually to be defined. This is because of limited image resolution, and because it is difficult to faithfully distinguish vessels from tracheid cells below a certain size. If a very narrow vessel that is smaller than the threshold size connects to an otherwise solitary wider vessel, the latter will appear as solitary in the results (see Fig. 1b). As a result, vessel grouping will be underestimated. Yet, since this affects all samples, no bias should be expected, unless the narrowest vessels below the cut-off size are more frequent in some of the samples. 
Furthermore, from a hydraulic efficiency point of view, the narrowest vessels contribute very little to overall conductivity (Fonti et al. 2010), although they may be important as a "safety net".

Second, if the cut runs through oblique reticulate or scalariform perforation plates between two joining vessels or vessel elements (cf. Fig. 1b), they may mistakenly appear as paired vessels from a cross-sectional perspective (Carlquist 2001). This situation may occur quite frequently when considering vessel element lengths of a few hundred microns. However, simple perforation plates between vessel elements seem to be more abundant in hardwood species than scalariform or reticulate perforation plates (Butterfield \& Meylan 1982).

Accordingly, vessel elements in $V$. thapsus are connected through simple perforation plates, while only intervessel pits are scalariform (Schweingruber 2005). Vessel grouping may also be systematically overestimated if the cutting plane is exactly through the branching of two vessels. This will be rather rare, however, because vessel branching does not occur extensively along the plant axis (André 2005); vessels rather connect through some axial contact length, which is correctly considered as grouping in this case. Some of these limitations could potentially be removed by $3 \mathrm{D}$ visualization techniques such as highresolution computed tomography (Brodersen et al. 2011; Brodersen et al. 2013), however, accessibility and current limitations with respect to image resolution and sample size, may pose challenges for more widespread application.

\section{Perspectives for vessel grouping analysis}

The presented example allows to anticipate the promises of future studies of vessel grouping. We demonstrated the value of characterizing vessel groupings - especially grouped versus solitary vessels - that is not possible through previously approaches of whole-sample analysis such as point pattern analysis (Loepfe et al. 2007; Mencuccini et al. 2010; Martínez-Vilalta et al. 2012). Yet, we expect that for a full understanding of structure-function relationships of the xylem hydraulic system further grouping indices than those proposed here will be needed. The additional parameters suggested in this paper serve as examples for moving beyond the well-established vessel grouping index $V_{G}$ - which is a mean value with limited functional information - and characterizing also variation of vessel grouping. We hope that this paper stimulates innovation towards the most useful quantification of spatial vessel arrangement. Particularly, quantification of vessel size-dependent grouping may prove to better connect structural with functional xylem properties under environmental variability. It is well possible, for example, that quantifying vessel size-dependent grouping should extend to the question of whether two grouped vessels are of similar or different size. In this sense, automated image analysis as performed by ROXAS opens the door for new types of data analyses.

\section{Conclusions}

The image analysis tool ROXAS accurately calculated established and novel aspects of vessel grouping patterns. Thanks to its efficiency entire cross-sectional samples can be analyzed, which likely provides sufficiently large numbers of vessel measurements to detect relatively small differences within species and even among annual rings of individuals. The large number of vessels analyzed by ROXAS therefore constitutes an important methodological advancement. Other key advantages of automated quantification of vessel grouping lie within its objectivity and reproducibility.

Vessel grouping is a very poorly investigated functional trait of the xylem hydraulic system. Parameters used so far are rather simple and probably insufficient to cover the various 
311 functional meanings. Particularly unexplored parameters such as the frequency distribution of 312 vessel group sizes, and the percentage of grouped (vs. solitary) vessels among different vessel 313 size classes may prove to be of great ecological relevance and should therefore be considered 314 in future studies. In addition, a better characterization of the structural context of vessels 315 such as the size of the vessels involved in grouping - may be necessary to understand whether 316 vessel grouping is beneficial during water limitation. Thanks to its versatility, applications of 317 ROXAS might also contribute to systematic studies that built on vessel grouping analyses 318 (e.g. Lens et al. 2009), or to test hypotheses developed for woody species with herbaceous 319 species (e.g. Lens et al. 2013). 


\section{Acknowledgements}

323 This work was partly supported by grants from Swiss National Science Foundation (PBEZA-

324 117266) to GvA, and the USDA National Institute of Food and Agriculture Biology of Weedy 325 and Invasive Species Program (NRI grant no. 2006-35320-17360) and ETH Zurich to CK.

326 This study profited from discussions within the framework of the COST Action STReESS. 


\section{References}

Alder NN, Pockman WT, Sperry JS, Nuismer S. 1997. Use of centrifugal force in the study of xylem cavitation. Journal of Experimental Botany 48(3): 665-674.

André J-P. 2005. Vascular organization of angiosperms: a new vision. Science Publishers Inc., Enfield, NH, USA.

Arbellay E, Fonti P, Stoffel M. 2012. Duration and extension of anatomical changes in wood structure after cambial injury. Journal of Experimental Botany 63(8): 3271-3277.

Baas P, Carlquist S. 1985. A comparison of the ecological wood anatomy of the floras of Southern-California and Israel Iawa Bulletin 6(4): 349-353.

Baas P, Schweingruber FH. 1987. Ecological trends in the wood anatomy of trees, shrubs and climbers from Europe Iawa Bulletin 8(3): 245-274.

Baas P, Werker E, Fahn A. 1983. Some ecological trends in vessel characters. Iawa Bulletin 4: 141-159.

Brodersen CR, Lee EF, Choat B, Jansen S, Phillips RJ, Shackel KA, McElrone AJ, Matthews MA. 2011. Automated analysis of three-dimensional xylem networks using highresolution computed tomography. New Phytologist 191(4): 1168-1179.

Brodersen CR, McElrone AJ, Choat B, Lee EF, Shackel KA, Matthews MA. 2013. In vivo visualizations of drought-induced embolism spread in Vitis vinifera. Plant Physiology 161(4): 1820-1829.

Butterfield BG, Meylan BA. 1982. Cell wall hydrolysis in the tracheary elements of the secondary xylem. In: Baas P ed. New perspectives in wood anatomy: 71-84. Dr W. Junk Publishers, The Hague.

Cai J, Tyree MT. 2010. The impact of vessel size on vulnerability curves: data and models for within-species variability in saplings of aspen, Populus tremuloides Michx. Plant Cell And Environment 33(7): 1059-1069.

Carlquist S. 1966. Wood anatomy of Compositae: a summary, with comments on factors controlling wood evolution. Aliso 6(2): 25-44.

Carlquist S. 1984. Vessel grouping in dicotyledon wood: significance and relationship to imperforate tracheary elements. Aliso 10(4): 505-525.

Carlquist S. 2001. Comparative wood anatomy: systematic, ecological, and evolutionary aspects of dicotyledon wood. Springer, Berlin.

Carlquist S. 2009. Non-random vessel distribution in woods: patterns, modes, diversity, correlations. Aliso 27: 39-58.

Carlquist S. 2012. How wood evolves: a new synthesis. Botany 90(10): 901-940.

Fonti P, Eilmann B, Garcia-Gonzalez I, von Arx G. 2009. Expeditious building of ring-porous earlywood vessel chronologies without loosing signal information. Trees-Structure and Function 23(3): 665-671.

Fonti P, von Arx G, García-González I, Eilmann B, Sass-Klaassen U, Gärtner H, Eckstein D. 2010. Studying global change through investigation of the plastic responses of xylem anatomy in tree rings. New Phytologist 185: 42-53.

Hacke UG, Jacobsen AL, Pratt RB. 2009. Xylem function of arid-land shrubs from California, USA: an ecological and evolutionary analysis. Plant, Cell \& Environment 32(10): 13241333.

Hacke UG, Sperry JS. 2001. Functional and ecological xylem anatomy. Perspectives in Plant Ecology, Evolution and Systematics 4(2): 97-115.

Holtta T, Vesala T, Peramaki M, Nikinmaa E. 2006. Refilling of embolised conduits as a consequence of 'Munch water' circulation. Functional Plant Biology 33(10): 949-959.

Jansen S, Gortan E, Lens F, Lo Gullo MA, Salleo S, Scholz A, Stein A, Trifilò P, Nardini A. 2011. Do quantitative vessel and pit characters account for ion-mediated changes in the hydraulic conductance of angiosperm xylem? New Phytologist 189(1): 218-228. 
Kueffer C, Daehler CC, Torres-Santana CW, Lavergne C, Meyer JY, Otto R, Silva L. 2010. A global comparison of plant invasions on oceanic islands. Perspectives in Plant Ecology Evolution and Systematics 12(2): 145-161.

Lens F, Endress ME, Baas P, Jansen S, Smets E. 2009. Vessel grouping patterns in subfamilies Apocynoideae and Periplocoideae confirm phylogenetic value of wood structure within Apocynaceae. American Journal of Botany 96(12): 2168-2183.

Lens F, Sperry JS, Christman MA, Choat B, Rabaey D, Jansen S. 2011. Testing hypotheses that link wood anatomy to cavitation resistance and hydraulic conductivity in the genus Acer. New Phytologist 190(3): 709-723.

Lens F, Tixier A, Cochard H, Sperry JS, Jansen S, Herbette S. 2013. Embolism resistance as a key mechanism to understand adaptive plant strategies. Current Opinion in Plant Biology 16(3): 287-292.

Loepfe L, Martinez-Vilalta J, Pinol J, Mencuccini M. 2007. The relevance of xylem network structure for plant hydraulic efficiency and safety. Journal of Theoretical Biology 247(4): 788-803.

Lopez BC, Sabatae S, Gracia CA, Rodriguez R. 2005. Wood anatomy, description of annual rings, and responses to ENSO events of Prosopis pallida HBK, a wide-spread woody plant of arid and semi-arid lands of Latin America. Journal of Arid Environments 61(4): 541-554.

Martínez-Vilalta J, Mencuccini M, Álvarez X, Camacho J, Loepfe L, Piñol J. 2012. Spatial distribution and packing of xylem conduits. American Journal of Botany 99(7): 11891196.

Mencuccini M, Martinez-Vilalta J, Piñol J, Loepfe L, Burnat M, Alvarez X, Camacho J, Gil D. 2010. A quantitative and statistically robust method for the determination of xylem conduit spatial distribution. American Journal of Botany 97(8): 1247-1259.

Nardini A, Dimasi F, Klepsch M, Jansen S. 2012. Ion-mediated enhancement of xylem hydraulic conductivity in four Acer species: relationships with ecological and anatomical features. Tree Physiology 32(12): 1434-1441.

Parker IM, Rodriguez J, Loik ME. 2003. An evolutionary approach to understanding the biology of invasions: Local adaptation and general-purpose genotypes in the weed Verbascum thapsus. Conservation Biology 17(1): 59-72.

Robert EMR, Koedam N, Beeckman H, Schmitz N. 2009. A safe hydraulic architecture as wood anatomical explanation for the difference in distribution of the mangroves Avicennia and Rhizophora. Functional Ecology 23(4): 649-657.

Sano Y, Morris H, Shimada H, Ronse De Craene LP, Jansen S. 2011. Anatomical features associated with water transport in imperforate tracheary elements of vessel-bearing angiosperms. Annals of Botany 107(6): 953-964.

Scholz A, Klepsch M, Karimi Z, Jansen S. 2013. How to quantify conduits in wood? Frontiers in Plant Science 4.

Schweingruber FH. 2005. The xylem database. Birmensdorf. URL: http://www.wsl.ch/dendro/xylemdb [accessed 17 June 2013]

Seipel T, Alexander JM, C.C. D, Edwards PJ, Dar PA, McDougall K, B. N, Parks C, Reshi ZA, Rew LJ, Schroder M, Kueffer C. 2013. Home and away: performance of an invasive plant in native and non-native regions. Journal of Biogeography. In revision.

Sperry JS, Tyree MT. 1988. Mechanism of water stress-induced xylem embolism. Plant Physiology 88(3): 581-587.

Tyree MT, Davis SD, Cochard H. 1994. Biophysical perspectives of xylem evolution: is there a tradeoff of hydraulic efficiency for vulnerability to dysfunction? . Iawa Journal 35: 335-360.

Tyree MT, Ewers FW. 1991. The hydraulic architecture of trees and other woody-plants. New Phytologist 119(3): 345-360. 
von Arx G, Archer SR, Hughes MK. 2012. Long-term functional plasticity in plant hydraulic architecture in response to supplemental moisture. Annals of Botany 109(6): 1091-1100. von Arx G, Dietz H. 2005. Automated image analysis of annual rings in the roots of perennial forbs. International Journal of Plant Sciences 166(5): 723-732. von Arx G, Dietz H. 2006. Growth rings in the roots of temperate forbs are robust annual markers. Plant Biology 8: 224-233. woody Rosaceae and other vesselled plants: a basis for a safety versus efficiency tradeoff in xylem transport. Plant, Cell \& Environment 28(6): 800-812.

Zimmermann MH. 1983. Xylem structure and the ascent of sap. Springer, Berlin. 
441 Table 1. Parameters of vessel grouping calculated with the image analysis tool ROXAS.

\begin{tabular}{ll}
\hline Acronym & Definition \\
\hline$V_{G}$ & Vessel grouping index; mean number of vessels per group (counting a solitary \\
& vessel as 1, a pair of connected vessels as 2, etc.; Carlquist 2001) \\
$V_{S}$ & Vessel solitary fraction; ratio of solitary vessels to all vessels \\
$V_{M}$ & Mean group size of non-solitary vessels \\
$F D_{G}$ & Frequency distribution of different group sizes \\
$R G_{V A}$ & Percentage of grouped (non-solitary) vessels per vessel size class \\
\hline
\end{tabular}


445 Table 2. Comparison of vessel grouping parameters quantified with automatic ROXAS and manual inspection method for 3 randomly chosen 446 individuals. See Table 1 for explanation of the acronyms of the vessel grouping parameters .

\begin{tabular}{|c|c|c|c|c|c|c|c|c|c|c|c|c|c|c|c|c|}
\hline & \multirow[t]{2}{*}{ Method } & \multirow[t]{2}{*}{$V_{G}$} & \multirow[t]{2}{*}{$V_{S}$} & \multirow[t]{2}{*}{$V_{M}$} & \multicolumn{12}{|c|}{$F D_{G}$ (no. of vessels per group size) } \\
\hline & & & & & 1 & 2 & 3 & 4 & 5 & 6 & 7 & 8 & 9 & 10 & 11 & 12 \\
\hline \multirow{2}{*}{ Moist 1} & ROXAS & 1.096 & 0.837 & 2.155 & 1351 & 111 & 10 & - & 1 & - & - & 1 & - & - & - & - \\
\hline & Visual & 1.096 & 0.851 & 2.191 & 1374 & 96 & 12 & - & 1 & - & - & 1 & - & - & - & - \\
\hline \multirow[t]{2}{*}{ Moist 2} & ROXAS & 1.112 & 0.809 & 2.123 & 1121 & 109 & 46 & - & - & - & - & - & - & - & - & - \\
\hline & Visual & 1.137 & 0.778 & 2.186 & 1192 & 128 & 27 & 1 & - & - & - & - & - & - & - & - \\
\hline \multirow[t]{2}{*}{ Dry 1} & ROXAS & 1.434 & 0.504 & 2.563 & 2094 & 534 & 161 & 72 & 21 & 7 & 3 & 3 & 2 & - & - & 1 \\
\hline & Visual & 1.412 & 0.526 & 2.602 & 2185 & 478 & 163 & 80 & 22 & 5 & 4 & 3 & 3 & 1 & 1 & - \\
\hline
\end{tabular}

447 

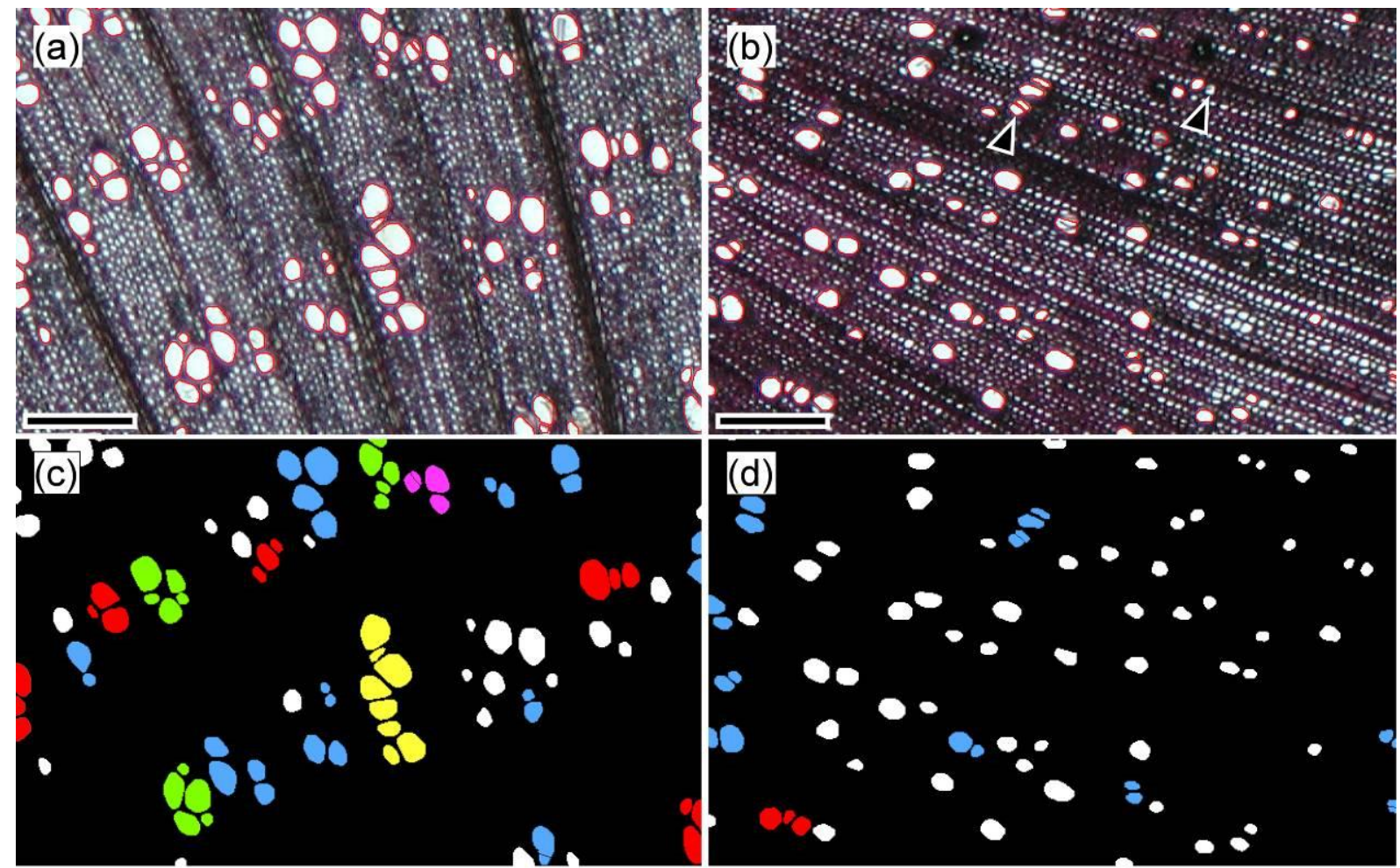

\begin{tabular}{r|c|r}
1.90 & $V_{G}$ & 1.19 \\
0.29 & $V_{S}$ & 0.70 \\
3.00 & $V_{M}$ & 2.09 \\
& Vessel group size $F D_{G}(\%):$ & \\
29.0 & $\square-1$ & 72.3 \\
25.8 & $\square-2$ & 24.1 \\
16.1 & $\square-3$ & 3.6 \\
4.3 & $\square-4$ & - \\
16.1 & $\square-5$ & - \\
8.6 & $\square-8$ & -
\end{tabular}

Fig. 1. Root cross-sections (cut-out images) of Verbascum thapsus from a dry (a,c) and moist grouping patterns. (a,b) Original images with outlines of considered vessels in red. $(c, d)$ Binary images of considered vessels with vessels belonging to different vessel group sizes depicted in different colors and values of several vessel grouping parameters given below. The left arrow in (b) indicates a paired vessel that might actually be overlapping ends of two vessels. The right arrow in (b) shows a vessel that was excluded because of the lower cut-off vessel size. See Table 1 for explanations of acronyms of vessel grouping parameters. Scale 
a) $V_{G}=1.50, V_{S}=0.50, V_{M}=3.00$
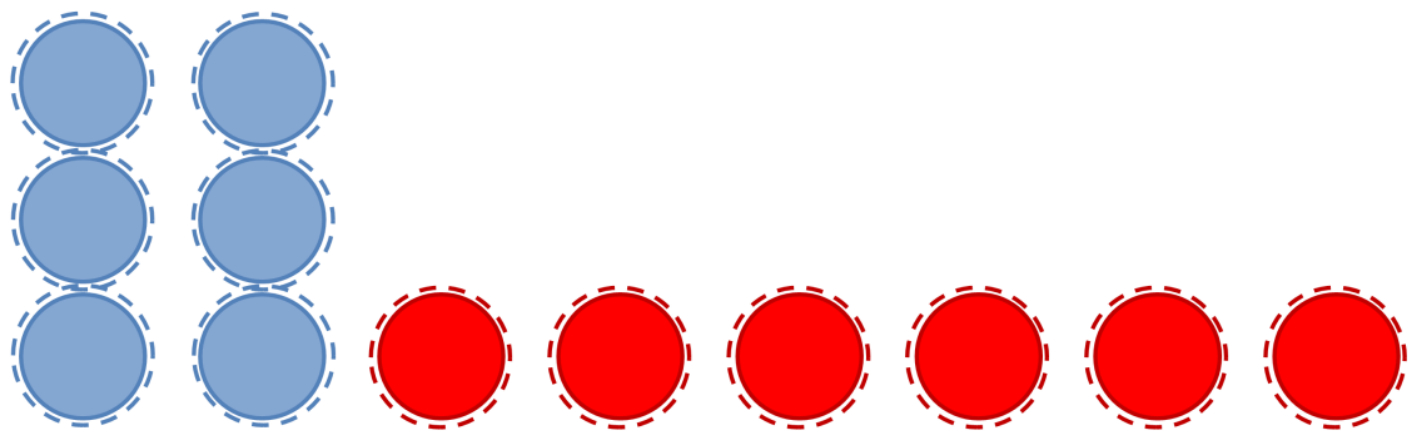

b) $v_{G}=1.50, v_{S}=0.33, v_{M}=2.00$
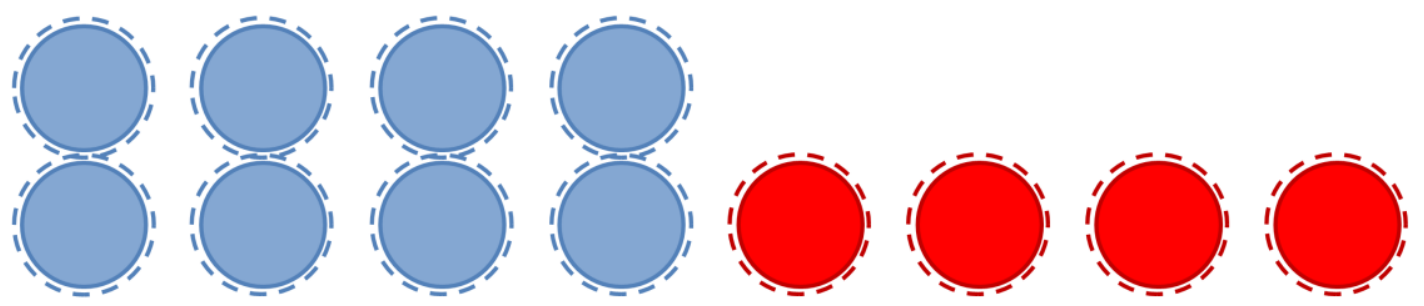

Fig. 2. The same vessel grouping index $V_{G}$ can be attained by a setup of differently large vessel groups $V_{M}$ and a different vessel solitary fraction $V_{S}$. In the example of panel (a) with totally 12 vessels, 6 vessels belong to two groups of 3 vessels each, while 6 vessels are solitary. In the example of panel (b), 8 vessels belong to four groups of 2 vessels, while only 4 vessels are solitary. The hydraulic integration in (b) is therefore greater than in (a). Vessel lumen area is depicted by filled areas while the outlines of vessel walls are schematically represented by dashed lines. 


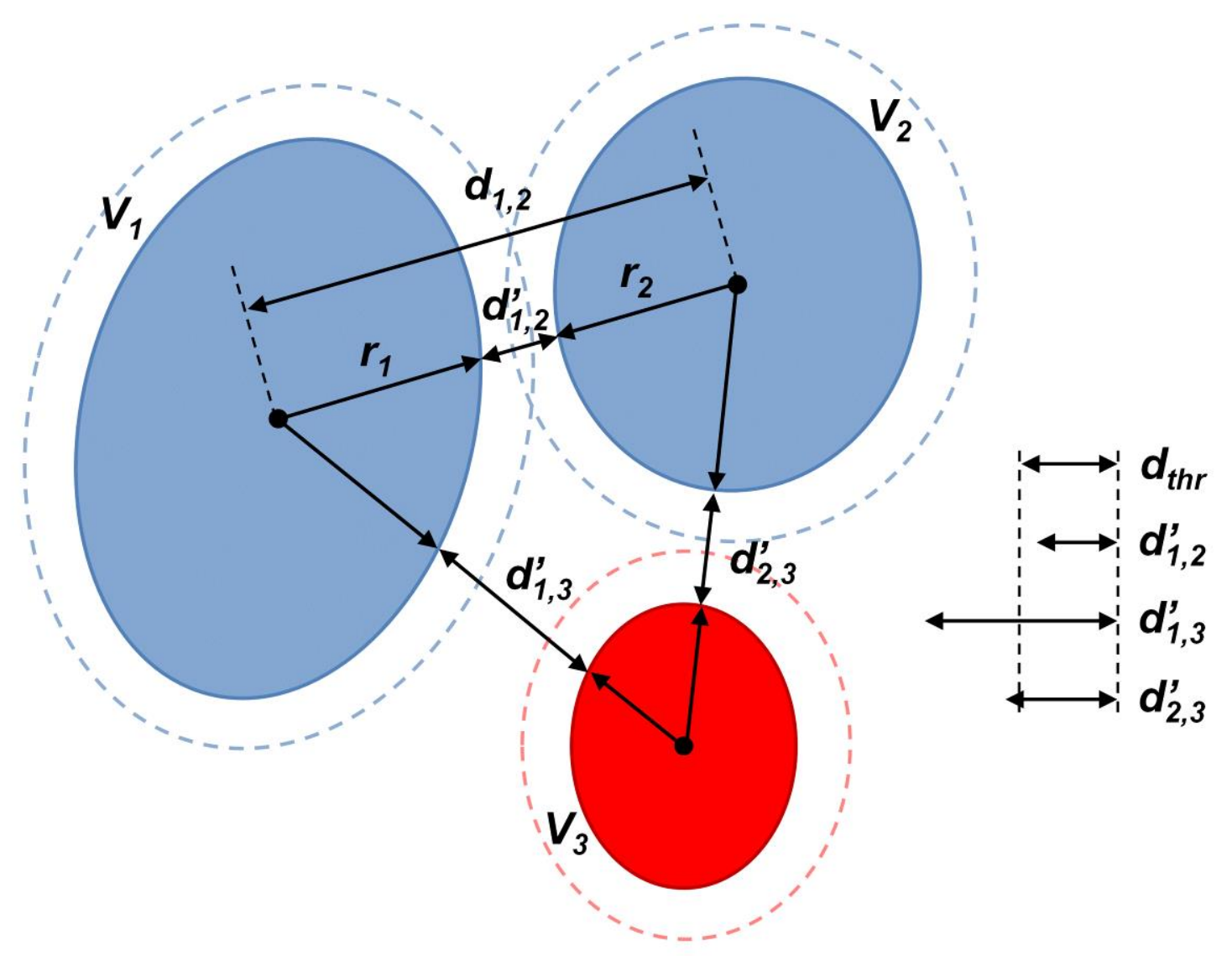

472 Fig. 3. Conceptual model of how ROXAS distinguishes grouped from solitary vessels. The vessels are first expressed as their area-equivalent ellipses. Taking the example of vessels \#1 $\left(V_{l}\right)$ and \#2 $\left(V_{2}\right)$, the distance $d_{l, 2}$ between the centroids of $V_{l}$ and $V_{2}$ is then calculated. From $d_{1,2}$, the radii $r_{1}$ and $r_{2}$ along the connection between the centroids is then subtracted to yield the distance $d_{1,2}^{\prime}$ between the outlines of the two ellipses. If $d_{1,2}^{\prime}$ is smaller than a threshold $d_{t h r}$, which approximately corresponds to twice the thickness of average vessel walls, the two vessels are assumed to be grouped. Vessel lumen area is depicted by filled areas while the outlines of vessel walls are schematically represented by dashed lines. 


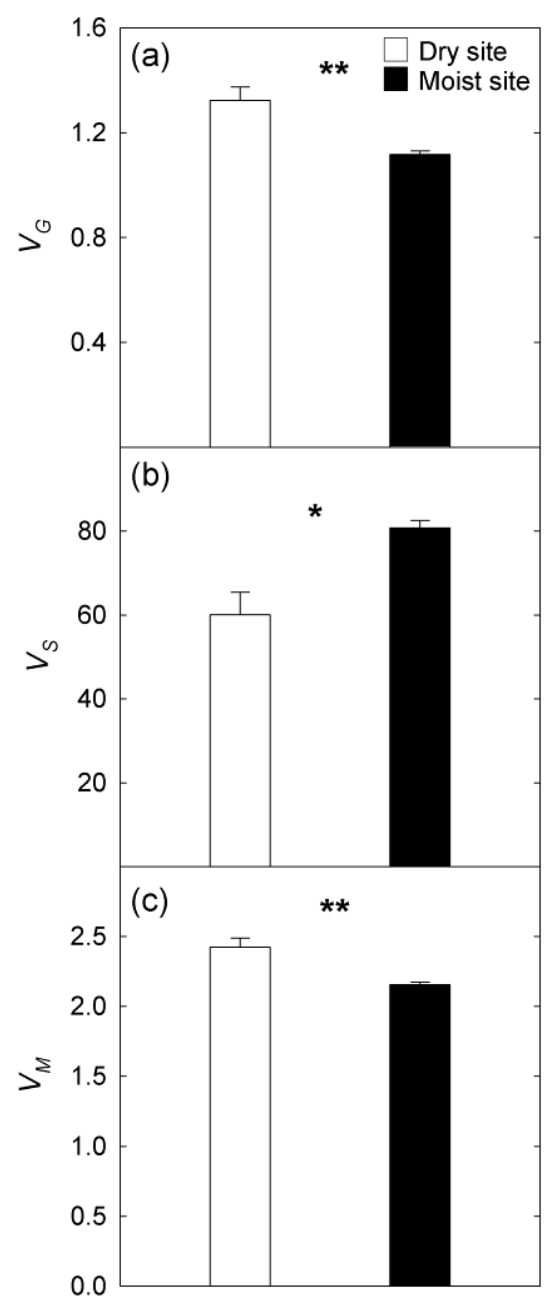

Fig. 4. Differences in a) vessel grouping index $\left(V_{G}\right)$, b) vessel solitary index $\left(V_{S}\right)$, and c) mean 484 485 group size of non-solitary vessels $\left(V_{M}\right)$ in Verbascum thapsus growing at a dry $(\mathrm{n}=6)$ and moist site $(\mathrm{n}=8)$ on Big Island, Hawaii, USA (mean \pm 1 se). Statistical significance based on t486 487 tests, $*-\mathrm{P} \leq 0.05, * *-\mathrm{P} \leq 0.01$ 


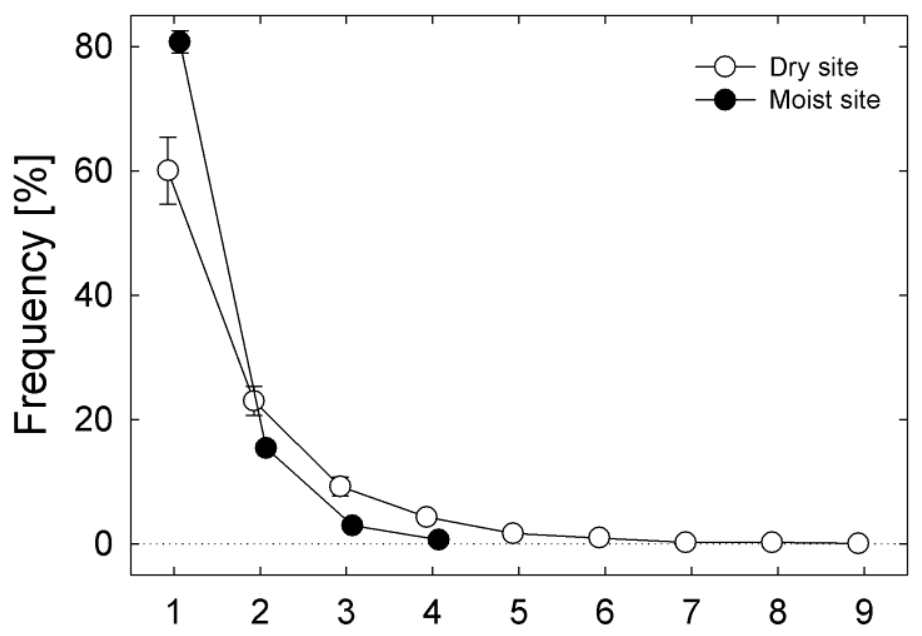

Vessel group size

Fig. 5. Relative frequency of different vessel group sizes (including solitary vessels as groups of 1) in Verbascum thapsus growing at a dry and a moist site on Big Island, Hawaii, USA (mean \pm 1 se). Vessel group sizes containing overall $<25$ vessels (when multiplying a specific group size by the number of such groups) are not shown. Symbols within vessel group sizes are jittered for better readability. 


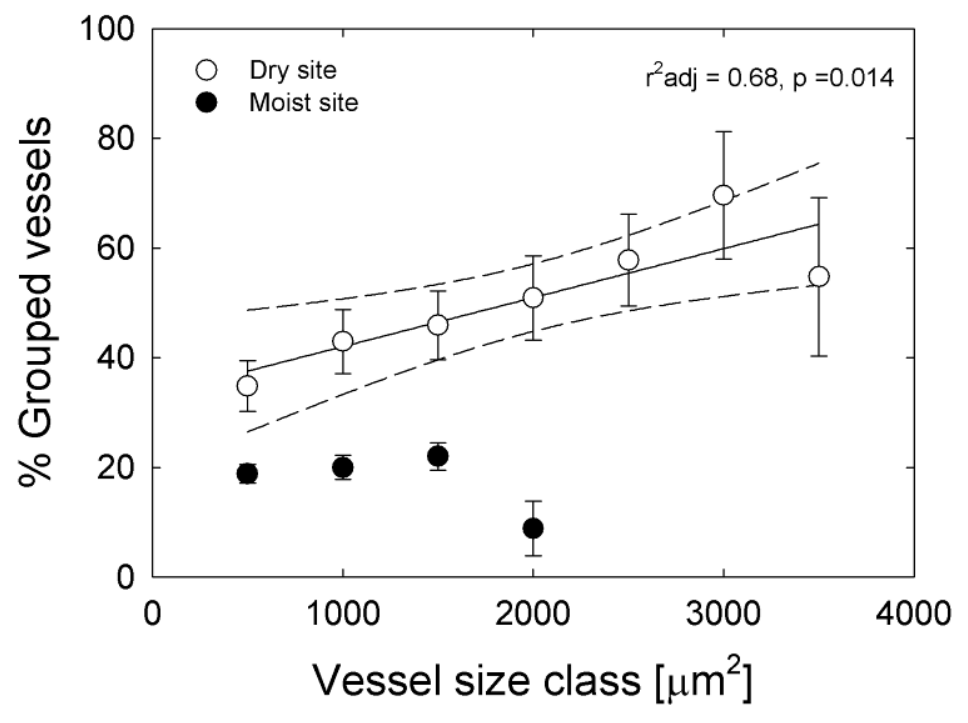

498 Fig. 6. The percentage of grouped vessels per vessel size class in Verbascum thapsus growing 499 at a dry and a moist site on Big Island, Hawaii, USA (mean \pm 1 se). Unlike at the moist site, 500 grouping increased with vessel size in plants growing at the dry site. Only vessel size classes 501 with $\geq 25$ vessels included. Solid line - linear regression. Dashed line $-95 \%$ confidence band. 